\title{
Ansichten eines Menschen mit Herz für Tiere...
}

\author{
Piero Lercher im amüsanten Gespräch mit dem charismatischen Präsidenten des \\ WWF-Österreich Dr. Helmut Pechlaner
}

Entwicklungsgeschichtlich beginnt das Herz am 23 oder 24. Tag der Embryonalentwicklung mit peristaltischen Kontraktionen zu pulsieren. Das faszinierende Organ, welches in vielen Kulturen als bildliches Symbol für Liebe, Seele und Güte gilt, wird bis zum Lebensende pumpen - ohne Pause, Urlaub oder Krankenstand.

Nachfolgend kommt Dr. Helmut Pechlaner zu Wort, der sich mit enormer Ausdauer und Güte für die Erhaltung von bedrohten Tierarten einsetzt.

Sehr geehrter Herr Dr. Pechlaner, sie sind ein Mensch mit dem Herzen ,am rechten Fleck" und setzen sich auch äußerst engagiert für die Tierwelt ein. Dafür benötigt man ein „großes“ Herz, aber auch sehr viel Kraft und Ausdauer. Wie halten Sie sich für diese verantwortungsvolle Aufgabe fit? HELMUT PECHLANER: Basis ist meine glückliche, robuste genetische Mitgift. Ausdauer brauchte ich für mein Nervenkostüm, da helfen nur Erholungsphasen (In der Ruhe liegt die Kraft!).

Wie sieht Ihre persönliche Herzvorsorge aus?

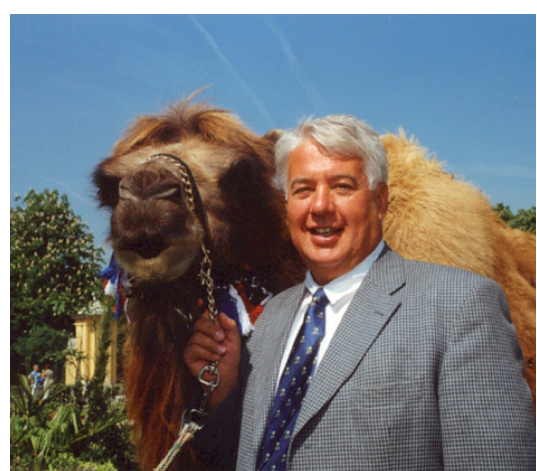

Helmut Pechlaner mit großem Herz für Tiere

$$
\begin{aligned}
& \text { Anmerkung der Redaktion: die weltweit erste } \\
& \text { erfolgreiche Herztransplantation am Menschen } \\
& \text { erfolgte am 3. Dezember } 1967 \text { durch den Chirur- } \\
& \text { gen Christiaan Barnard am Patienten Louis } \\
& \text { Washkansky im Groote-Schuur-Krankenhaus in } \\
& \text { Kapstadt, Südafrika }
\end{aligned}
$$

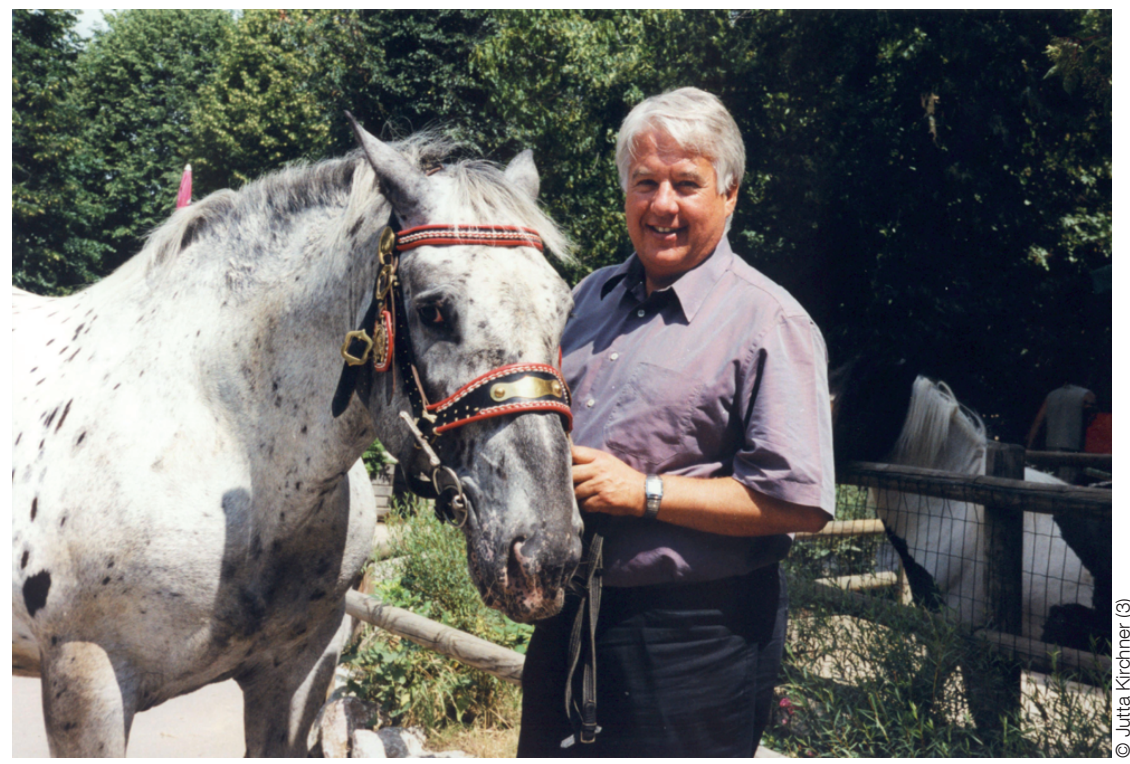

...der Pferdeflüsterer...

H.P.: Seit jeher regelmäßige ärztliche Kontrolle, gemütliches Ausdauertraining, regelmäßiger Weingenuss zur Freude und gegen Verkalkung.

Existieren vorbildhafte präventivmedizinische Maßnahmen in der Veterinärmedizin? Wenn ja, welche?

H.P.: Gute Zootierhaltung zeigt, dass artgemäßes Leben sehr lange gesund erhält und kaum einer medizinischem Betreuung bedarf.

Welche ärztliche oder humanmedizinische Errungenschaft hat Sie am meisten beeindruckt?
H.P.: Die erste Herztransplantation.*

Mit welchen Argumenten würden Sie die Menschen zu mehr gesundheitlicher Eigenverantwortung animieren? H.P.: Fast alle Aktionen und Aktivitäten der Menschen sind nur über ihren Egoismus zu steuern.

Kann das Tier dem Menschen als Vermittler von Gesundheitsbewusstsein dienen?

H.P.: Tiere können Menschen unverzichtbare Sozialkontakte ersetzen. Daraus resultieren Wohlfühlen und Zufriedenheit, die Basis der Gesundheit. 